\title{
Culture Influence on the Perception of the Body Language by Arab and Malay Students
}

\author{
Marzieh Gordan (Corresponding author) \\ School of Language Studies and Linguistics, University Kebangsaan Malaysia \\ Tel: $00601129081892 \quad$ E-mail: marzieh.gordan@yahoo.com \\ Isai Amuthan Krishnan \\ Tel: 0123845100 E-mail: kisai27@yahoo.com.my \\ Zurina Khairuddin \\ Faculty of Languages and Communication, University Sultan Zainal Abidin \\ Tel: 0192406482 E-mail: zkzurina@unisza.edu.my
}

Received: 03-06-2013

doi:10.7575/aiac.ijalel.v.2n.6p.1
Accepted: 24-07-2013

Published: 01-11-2013

\begin{abstract}
Intercultural communication is applied for communicating with each other among the different cultures and traditions. It highlighted the problems which faced by different communities and organizations, the problems which are natural to the person like when the people face to new culture or tradition even the religious issues. So intercultural communication here is seeking for an answer between the different nations that how they communicate with each other when they face some problems in their tradition and culture. This one highlights how the people encode a message and how they interpret a message to each other. So here in this paper interaction is between students of Arabs and Malays from National University of Malaysia and it deals with their body language especially hand gestures. This paper is based on the Micheal Byram theory of language. In this quantitative research some questions will distribute among the students and the similarities and differences between their sign languages will be highlighted.
\end{abstract}

Keywords: culture influence, body language, hand gestures, Arab students, Malay students

\section{Introduction}

The early active body language our primitive ancestors shared was easily understood by all but the most inept among them. The most rudimentary communication was easy to recognize (Hartley \& Karinch 2009). Along with the human evolutionary path, we made great dicegences from our ape kin. Although our vocal organs do not differ significantly from chimpanzees, our desire is to be understood dramatically. As we evolve toward increasingly more communicative beings, simply using ubiquitous body language no longer suffice. We wanted to get our exact point across and to have the nuances be easily understood.

\section{Background of the study}

As Hartley and Karinch (2009: 89) in their Handbook of Body Language stated:

"Body language is the language that deals with signals, gesture and mood. Body language studies the analyses of the hands, feet, emotions communicated through movement, such as facial expressions and the movement of eyes, legs, and the whole body. Many studies state how the body language of someone can expose his or her state of mind and intentions, and personality traits such as self-confidence, shyness, aggressiveness, greed, rivalry. We can say that a person's posture expresses his or her attitudes and feelings. The real value of body language is found in the sum of all the levels of communication: oral language, visual language, body language, and imagination".

The aim of this paper was to investigate the similarities and differences between Malay and Arab students and to understand the signs of body language in face-to-face communication, especially in hand signs. Furthermore, it tends to analyze the feelings which come from actions and body languages, like expressions of a person's appearance and face and the eye's movement, hand gestures and the setting which is related to the times and act which will take place. Generally, the physical actions are different situations which mean the researcher will get the information from asking students in UKM University. This study highlighted that body language and gestures can make apparent the person's state of mind and behavior which they do, and it can be the reason for their confidence, feeling shy, being aggressive or acting as a greedy person. By this body language each individual tries is to show his or her inner feelings and emotions to one another. So knowing this knowledge and skill for us allows us to find out and understand the reason behind people's behavior and their action. 
The study was interested to find answers to the following questions:

1. What are the similarities between Arab and Malay in hand signs?

2. What are the differences between Arab and Malay in hand signs?

\section{Participants}

The researcher asked ten Universiti Kebangsaan Malaysia (UKM) Arab and Malay students with regards to ten hand signs.

\section{Data collection}

The data were collected through a questionnaire. A group of pictures was designed and after that they were shown to ten students who explained what they have understood about them.

\section{Theoretical framework}

According to Michael Byram (1997: 32-33):

"When persons from different languages and/or countries interact socially they bring to the situation their knowledge about their own country and that of the others'. Part of the success of such interaction will depend on the establishing and maintenance of human relationships, which depends on attitudinal factors. At the same time, both aspects, knowledge and attitude, are influenced by the processes of intercultural communication, that is, the skills of interpretation and establishing relationships between aspects of the two cultures and the skills of discovery and interaction".

With body language, one is able to convey his or her feelings, state of mind and emotions. He will be able to show his inner thoughts through body language. The relatively new form of communication, speech, fulfills the role of conveying information (facts and data) whilst the body fulfills the role of feelings. People tend to use the whole body to read a person's mood and attitudes and this is absorbed mainly at the unconscious level (Borg, 2008).

When we are communicating with friends, relatives, work colleagues or strangers, we have certain habits that are a part of us in a specific context or situation. If you are more aware of your body language, you will know which of these habits to change in order to improve relationships. It may not happen overnight, but you can gradually supplant these gestures or mannerisms. As Mark Twain (n.d.) stated:

"Habits cannot be thrown out the upstairs window. They have to be coaxed down the stairs one step at a time" (Cited in Borg, 2008: 4).

\section{Beginning of nonverbal communication}

Darwin (1872) began the study of body language in the 1800s. A ballet dancer turned-anthropologist named Ray Birdwhistell (1918-1994) picked up the ball in the 1970s and ran with it (Hagen, 2011). We have only been studying non-verbal communication, or body language, for around 50 years or so. Social anthropologists remind us that its origins go back to the beginning of time, before the spoken word. For most of us, the fascination of black and white 'silent' movies is as near as we get to appreciating how 'actions speak louder than words'. If you have seen the stars of the silent movie era, you will appreciate the power of this silent language (Allen \& Pease, 2006).

Whatever words we use during any interaction with people, they are, whether we like it or not, always accompanied by body talk which can reveal much more than the spoken word. Most people go about their business in all activities of their daily life wholly unaware that they are receivers and senders of non-verbal language (Borg, 2008).

\section{Body parts and body language}

This part will give readers an overview of almost every body part (limited to these parts that are on display in polite company, of course) in an effort to shed some light on the message emanating from these various areas. This section includes a brief overview of the regions of the body as they relate to body language.

"Most of the basic communication signals are the same all over the world. When people are happy, they smile, when they are sad or angry, they frown or scowl. Nodding the head is almost universally used to indicate 'yes' or affirmation. It appears to be a form of head lowering and is probably an inborn gesture because it's also used by people born blind. Shaking the head from side to side to indicate 'no' or negation is also universal and appears to be a gesture learned in infancy. When a baby has had enough milk, it turns its head from side to side to reject its mother's breast. When the young child has had enough to eat he shakes his head from side to side to stop any attempt to spoon-feed and, in this way, he quickly learns to use the heat-Shaking gesture to show disagreement or a negative attitude" (Allen \& Pease, 2006: 11).

$\checkmark$ Head: used for affirming (nodding) or (handshake) information. Various angels on the head are also used to convey an interest in what another person is saying.

$\checkmark$ Face: conveys emotion. The eyes are of particular interest, since you can snub someone simply by refusing to look his way.

$\checkmark$ Shoulders: used for showing lack of interest (Shrung: angling away from another person).

$\checkmark$ Arms: Can be used to express emotion; also used to make oneself look larger (hands-on-hips position). Arm crossing may indicate emotional discomfort, while flexing and expanding the arms is a way to express strong emotion (positive or negative). 
$\checkmark$ Hands: can be used in a variety of ways: to express emotion; to show camaraderie (handshake); to show discomfort (self-touches).

$\checkmark$ Legs: angling the legs to show interest; also, positioning of the legs can show power (wide stance) or fear (standing with legs crossed). Pigeon-toed people tend to look young, naïve, and sloppy (Hagen, 2011).

\section{Famous facial expressions}

There are some basic facial expressions which were accepted around the world already. These facial expressions are generally practiced by the people around the world and some of them are inculcated among the people. So these fundamental human emotions are considered as people's genetic characterization which is listed as below:

These emotional face expressions are:

$$
\begin{array}{ll}
\checkmark & \text { Feeling happy } \\
\checkmark & \text { Feeling sad } \\
\checkmark & \text { A sense of fear } \\
\checkmark & \text { A sense of disgust } \\
\checkmark & \text { A sense of surprise } \\
\checkmark & \text { Feeling angry }
\end{array}
$$

Charles Darwin's (1872) The Expressions of the Emotions in Man and Animals was a book which for the first time looked at these senses and feelings of human emotions and expressions. In this book, Darwin (1872) brought the theory of the Origin of Species which made a controversial argument among the thinkers. For many years there was a debate between thinkers because Darwin claimed that human emotions are inherited genetically and they get it from their family and parents and it goes from one generation to the other generation (1872).

In the 1960s, psychiatrists from California and experts in facial expressions, Ekman, Sorenson and Friesen (1969) brought up different information from the people of different groups and communities by using of Darwinian Theory. They claimed that all these expressions are universal and inherited among the people. And this is the people's ability to apply them in their different situations and circumstances in the life. Ekman, Sorenson and Friesen (1969) used some tribes which were isolated from the modern life and modern city and they were not westernized. This investigation showed that Darwin (1872) was right because these tribes were using those facial expressions which we already mentioned among them and they were applying basic human expressions in their daily life. So they conclude that these expressions are inculcated among all the people and hat their nature, and they genetically inherited.

\section{Intercultural communication}

Intercultural communication is applied for communicating with each other, with the different cultures and countries like the situation here between Arab and Malay students of UKM. It highlighted the problems which are faced by different communities and organizations, the problems which are natural to the person like different culture or tradition even the religious issues. So intercultural communication here is seeking for an answer between the different nations and how they communicate with each other when they face some problems in their tradition and culture. Hence, sometimes intercultural communication is used as cross cultural communication. This one highlights how the people encode a message and how they interpret a message to each other. Therefore, interaction between people is only between the people from other parts of the world who are not the citizens of a country since they all are familiar with their own messages and body languages. Like here, Arab and Malay students are from two different cultures.

\section{Hand gestures}

'Our nature consists in motion; complete rest is death' Pascal, Pensees (1670)

You probably know someone who's 'hand-talker', a person who can't make a point without doing so emphatically. He uses sweeping hand gestures, karate chops, and questionably timed claps and snaps, and occasionally positions his fingers as if to strangle an invisible victim. Your first introduction to a hand-talker can be startling, especially if you have never known anyone who communicates with his hands, or if the person in front of you is using gestures you have never seen and don't know how to interpret. Rest assured, hand-talking is an international occurrence.

\subsection{Famous hand gestures}

Hand gestures are different in all countries. But there are some gestures which are considered universal. Such as:

\footnotetext{
$\checkmark \quad$ The ' $\mathrm{V}$ ' for victory sign.

$\checkmark$ The 'okay' sign. Form a circle with the thumb and forefinger, and hold the other fingers straight up.

$\checkmark$ Thumb(s) up. This means 'nice work' in many cultures.

$\checkmark$ Waving. Says 'hello' or 'goodbye'

$\checkmark$ Temple-ing the hands or intertwining the fingers. In many cultures this conveys deep thought.

$\checkmark$ Hand(s) to the heart. This commonly indicates love or heartache.

$\checkmark$ Chopping motions, a fist, or finger pointed at someone's face or chest. All of these betray hostility in the speaker.

$\checkmark \quad$ The stop sign for stopping someone or something.

$\checkmark$ Pointing Fingers normally mean indicating someone or some object.

$\checkmark$ Crossed Fingers signify anticipation and good luck.
} 
There are many more hand gestures, of course. You use your hands to indicate the size and spatial relationships or to mimic activities. In fact, some researchers believe that the hands convey more meaning and emotions that the face or mouth.

\section{Arab body language}

The Arab people are living in 22 countries which are located in the Middle East. There is a term by the name of "Arabic culture" which is very difficult to define since all Arab countries are not the same and there are differences between their tradition and culture. There are also so a lot of similarities between all these countries, especially when we want to talk about particular features of both verbal and nonverbal communication (Benmoktar, 2009).

Body language has had many functions and meaning in all cultures especially among Arabs and Malaysians. In a way, a specific gesture or sign can convey an important meaning or state of mind of a person. In Arab culture, it's not only important what you try to say but the thing which is important is that how you express it; Although some gestures among Arabs are considered normal but they want to express it as it may be considered as an insult to them (Benmoktar, 2009). Below are some popular body languages which are famous and conventional by the Arab people:

\section{Eye Contact}

It is important mostly in business parties' which shows their attitude toward that deal through eye contacts. It is obviously not an accepted attitude if they gaze at the women because Arab countries are very sensitive to the second gender.

\section{$\checkmark$ Contemplation}

Arab people touch their chin with their thumb to show they are thinking about something or someone. This body language shows their wisdom and maturity.

\section{$\checkmark$ Calling}

To refer to a person by the hand and asking them to come to you by hand when you are moving your hand and fingers toward yourself down in Arab culture means "come here".

\section{$\checkmark$ No}

When Arab people tip their heads upwards and click their tongue, it means they do not agree with you and it shows their disagreement on something.

\section{$\checkmark$ Chill}

In the crowded streets of Arab countries, people hold their right hand like a shape of pear while they are moving their hand ups and down. It's a gesture that tries to say "be careful", or "slow down" when they are passing through the roads and streets.

\section{$\checkmark$ Thank you}

When Arabs try to say thank you, first they close their eyes, put their hand on their chest.

\section{$\checkmark \quad$ No respect for me}

It will be very rude in Arab culture if someone shows the soles of his feet while sitting down: it means for the person who are talking or sitting with "you are beneath my feet" (Benmoktar, 2009).

\section{Malaysians body language and customs}

If you were to come to Malaysia and visit this country, you should be familiar with the local customs and their specific gestures and sign languages. In Malaysia, both women and men's handshake when they see each other or when they want to leave each other. However, some conservative Muslim ladies do not shake hands and only nod their head as a goodbye or Salam. Traditionally, Malaysians hand shakes with both their hands; they always handshake from the bottom of their heart and respect the person whom they greet. Salam means handshake in Malaysia and it is not practiced in other countries. When it comes to respecting the holy places, a person who is going for names and prayer should take off his shoes before entering the mosque or the temple.

In terms of their food habit, all is eaten with their hands. They get the pleasure from eating with hands and not by spoon because they are traditional and follow their own custom and tradition and respect it although some of them, in some functions sometimes eat with spoon. Besides, the Chinese eat with chopsticks. Other than that, either Malays or Indians eat with their right hand by scooping up food using just the tips of your fingers. Moreover, one of the hand signs which are considered very insulting is that when you point your finger at someone.

\section{Analysis}

The aim of this paper was to investigate the similarities and differences between Malay and Arab students and to understand the signs of body language in face-to-face communication, especially in hand signs. Furthermore, it tends to analyze the feelings which come from actions and body languages, like expressions of a person's appearance and face and the eye's movement, hand gestures and the setting which is related to the times and act which will take place. Generally, the physical actions are different situations which mean the researcher will get the information from asking students in UKM University. This study highlighted that body language and gestures can make the person's state of mind and behavior which they do apparent, and it can be the reason for their confidence, feeling shy, being aggressive or acting as a greedy person. With this body language, each individual tries to show his or her inner feelings and emotions to one another. 
Table 1. Hand signs According to handbook of body language

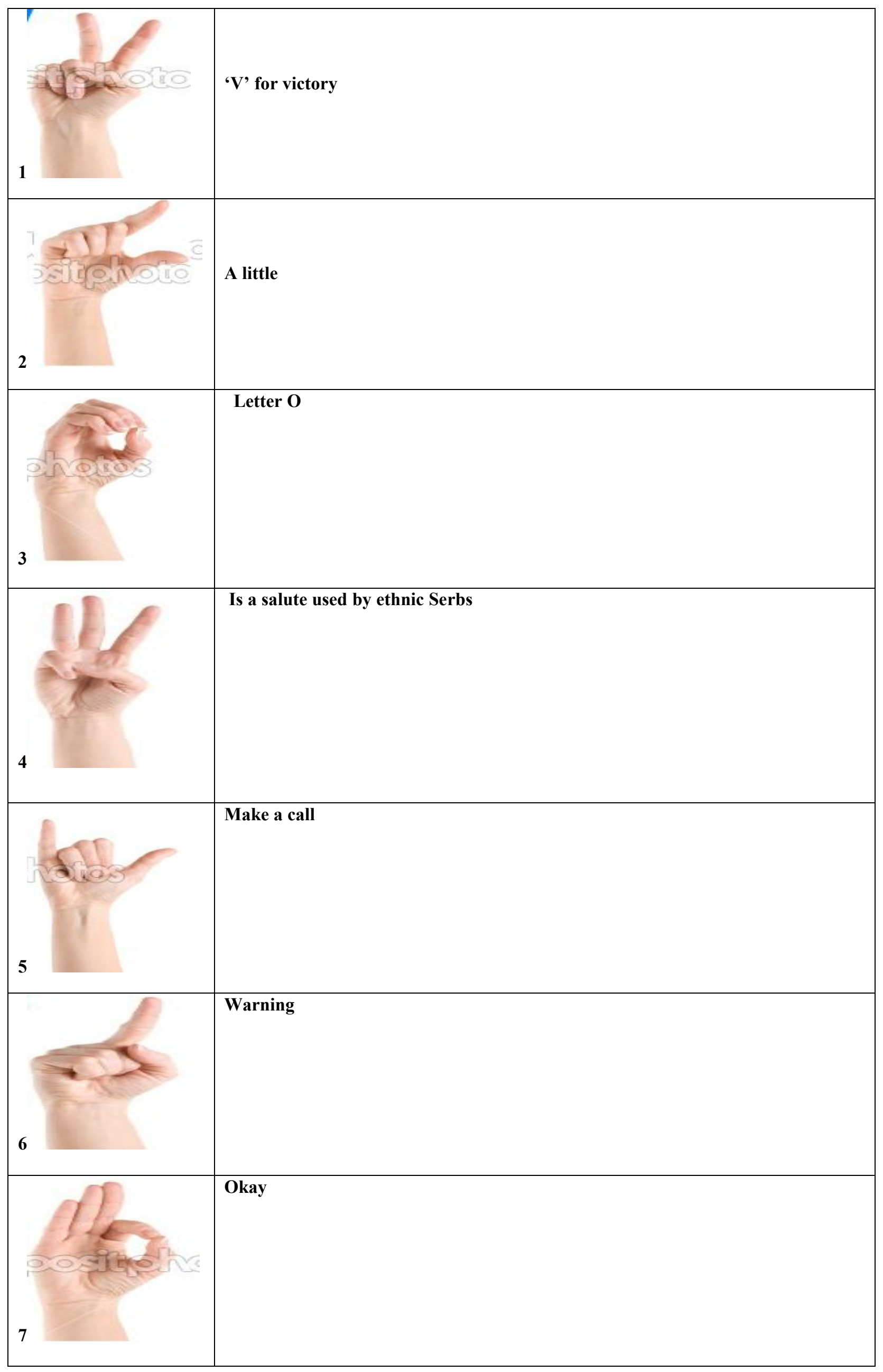




\begin{tabular}{|l|l|}
\hline & Opposite side \\
\hline 8 & \\
\hline
\end{tabular}

Thus, for this process, the researchers conducted some questions and distribute them to the chosen students. These students are only Arab and Malaysian students. These questions were about 10 hand gestures which are shown in Table 1 and the meanings are taken from the handbook of body languages.

The different answers between Arab and Malaysian students in UKM are shown in Table 2.

Table 2. Percentage of each sign language among Arab and Malaysian Students

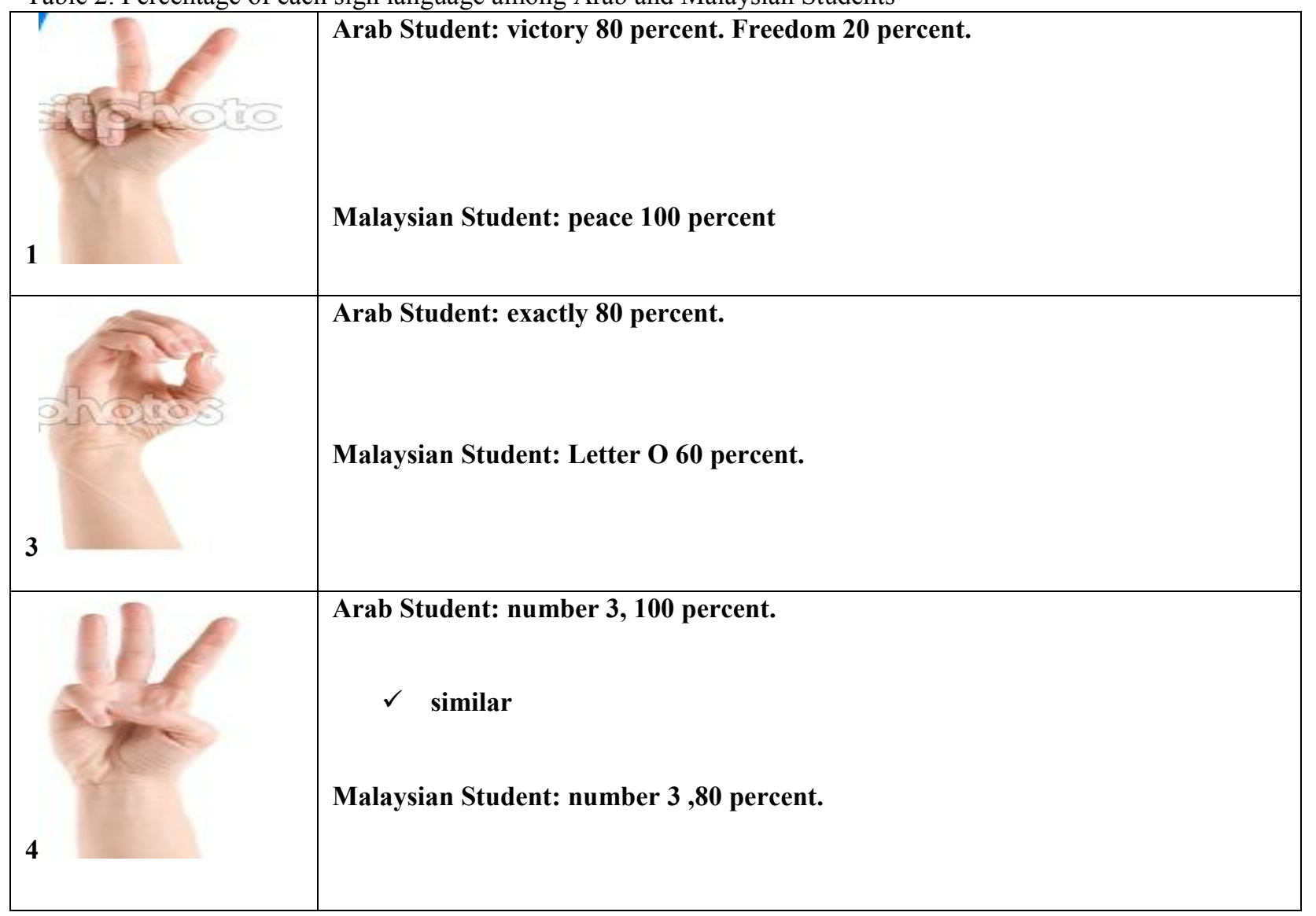




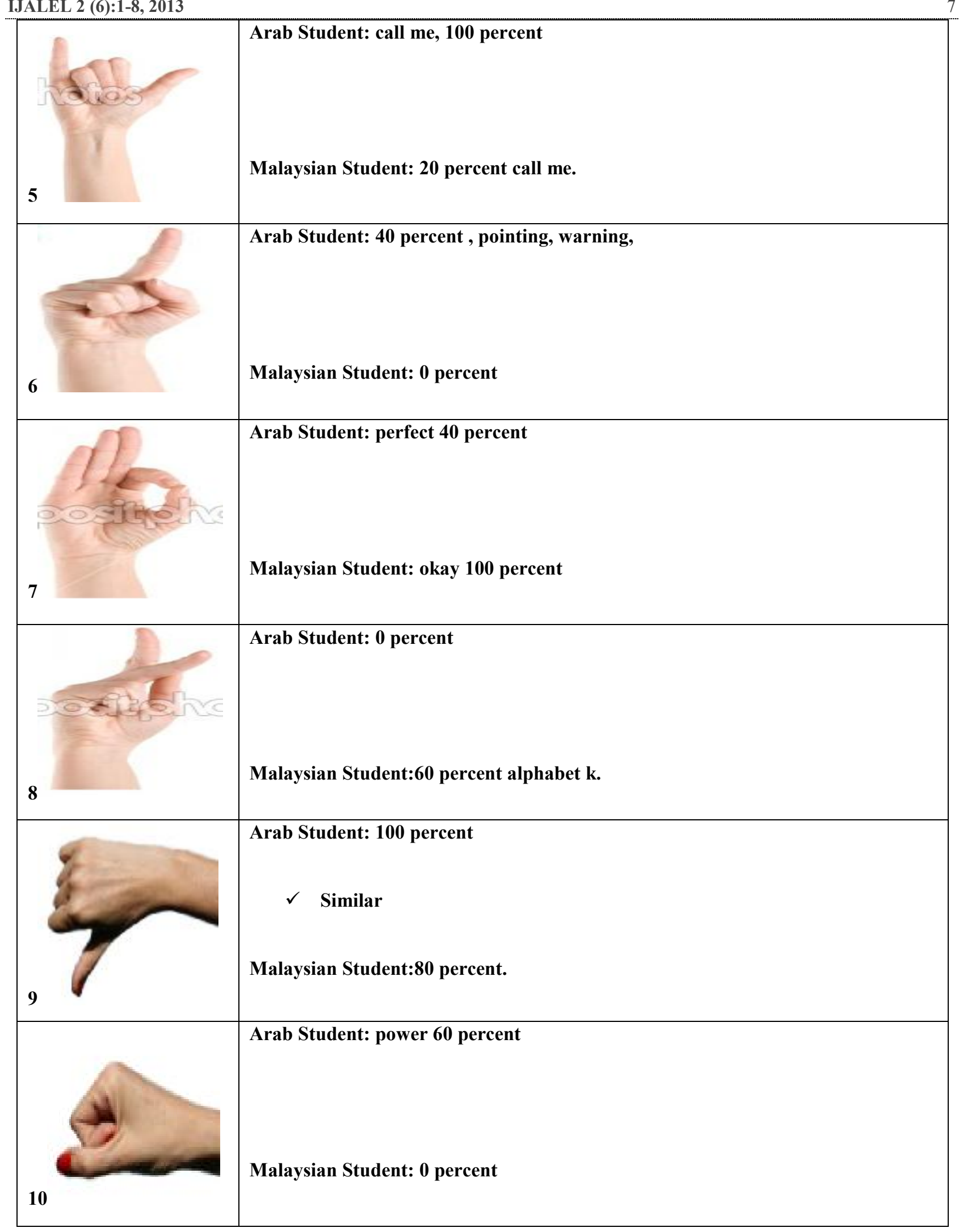

\section{Interpretations of Malay and Arab students of UKM}

Byram (1997) stated that when people from different countries come together, they share all their cultures and traditions because they have to interact with each other. They will have communications and relationships with each other. As a result, they will come to know the other culture and tradition especially their body language. These all depend on the degree of relationships which means how one is able to build this relationship and inculcate his or her way of life to the other. At this point the situation is different from that of students from UKM because these students have not been in Malaysia for a long time. Nevertheless, there are some cases which these people started a life with each other and they got married. Hence, in this case, one will be able to be more familiar with the other's body language; for example, in one culture's, one specific body language may not have a meaning for the partner but it may be very important for the other partner. Other than that, one specific body language may have a very bad meaning and may be considered as an insult but from the other side, it may not have a clear meaning like the examples which was shown before. Some sign languages may not have meanings for Malaysians but it may have meanings for Arab people in UKM. Apart from that, 
knowledge and attitude are two very important factors among the people; when they want to interact with each other. For example, all the students which have been chosen for this test are educated people and are from the academic area, thus this is a similarity among all students. However, there are only two specific sign languages which are similar and have the same meaning in both cultures (Number 4 and 9). Other than that, kissing parents' hand will be a sign of respect in both cultures. This shows that both Arabs and Malaysians have their own mentality since they don't stay in Malaysia for a long time and each culture has its roots although there are some similarities between their traditions and cultures.

The other important point which could be discussed is the differences between these groups of students. From the table, it can be concluded that Malaysians are not familiar with the general body language. It is clear that they do not use it in their daily interactions with each other and this relates to their culture. In some cultures, people communicate mostly through body language and sign language like eye contacts or hand gestures which can be seen as more apparent among Arab students. Since there are more differences, it can be concluded that Byram's (1997) idea can be applied to the people of two or more cultures and nationality in which they should make each other more familiar with their own lifestyle. Moreover, this can only be attained through their communications and relationships in their community and society. The effect of intercultural communication which is for communicating with each other can be seen even with the different cultures and countries like the Arab and Malaysian students of UKM. At UKM, a class of twenty can consist of different nationalities like Africans, Arabs, Malaysians, Iranians, Indonesians, Chinese and Koreans. Therefore, as mentioned, there is a relationship between the ability of the students in communication and the degree of their body language use. Some cultures may not use body language as much as others do, like Malaysians which is apparent from the table.

\section{Conclusion}

Researchers came up with a new idea that if a person changes his body language, he will be able to change different things about his approach to life. He or she is able to change his or her mood and idea for something. It can bring more confidence to the person when he is working or when he is communicating with people.

Everyone should know about their own specific body language. They should be aware what their body language conveys. To increase this awareness, one must know the knowledge of body language in a way that you should know that someone may look at you every second and you may convey something through your body language which may offend him. If individuals are familiar with body language, they will be able to have a better impact on someone especially when it is about business. This knowledge of being aware about our own body language and sign language will make us focus on other peoples' body language. Hence, each individual will have more control of his behavior and it leads to better communication process.

\section{References}

Allen \& Pease, B. (2004). The definitive book of body language. New York: Bantam Dell Publications.

Beattie, G. (2004). Visible thought: the new psychology of body language. USA \& Canada: Routledge.

Benmoktar, A. (2009). Arab body language. Retrieved on put the date you found this website from http://www.lovehabibi.com/blog/2009/07/02/more-than-words-arab-body-language/

Borg, J. (2008). Body Language: 7 easy lessons to master the silent language. Great Britain: Great Britain Publications.

Ekman, P., Sorenson, E. R., \& Friesen, W. V. (1969). Pancultural elements in facial displays of emotion. Science, 164 (3875), 86-88

Byram, M. (1997). Teaching and Assessing Intercultural Communicative Competence. Clevedon: Multilingual Matters. Hagen, S. (2011). The body language book ( $2^{\text {nd }}$ ed.). USA: Advantage Quest Publications.

Hartely, G. \& Karinch. M. (2009). The body language handbook: how to read everyone's hidden thoughts and intentions. USA: Advantage Qyest Publications.

Goman, C, K. (2011). The silent language of leaders. San Francisco, CA: Jossey-Bass Publications.

Richmond, V. \& McCroskey, J. C. (1995). Nonverbal behavior in interpersonal relations. Electoronic Publishing Services: West Virgina University. 